\title{
Self-assessment of Mental Health Among Students of Iran University of Medical Sciences
}

Mahnaz Solhi

Associate Professor, Dept. of Health Education and Promotion, Faculty of Health, University of Health, University of Medical Sciences, Tehran, Iran

Razieh Pirouzeh

* PhD Candidate, Dept. of Health Education and Promotion, Faculty of Health, University of Health, University of Medical Sciences, Tehran, Iran. (Corresponding Author).r_pirouzeh@ yahoo.com

Zahra Rahimi Khalifeh Kendi3 PhD Candidate, Dept. of Health Education and Promotion, Faculty of Health, University of Health, University of Medical Sciences, Tehran, Iran

Received: 20 December 2018 Accepted: 26 June 2019 DOI: 10.30699/ijhehp.7.3.339

\section{ABSTRACT}

Background and Objective: The students studying at the universities of medical sciences deal with numerous stressors during their educational experiences in the healthcare settings, which lead to poor mental health status and low performance. Regarding the role of students in the provision, maintenance and promotion of community health, this study was aimed to determine the self-assessment of mental health among students of Iran University of Medical Sciences.

Materials and Methods:In this descriptive-analytical study, 300 students of the 8600 Iranian medical sciences students were randomly selected. The data collection was performed using a demographic form and a researcher-made questionnaire on self-assessment of mental health, validity and reliability of which were obtained. Data was analyzed by SPSS 16 using descriptive index and analytical tests at a significant level of 0.05 .

Results: The mean and standard deviation of self-assessment of students' mental health was $89.08 \pm 13.12$. Also $14.7 \%$ of the students reported their mental health as poor, $70.3 \%$ as moderate and $15 \%$ as good. The mean age of the students was $25 \pm 6.21$ years. The mean score of dimensions of ability to overcome anger and anger, the ability to balance the rest and activity and the ability to overcome anxiety were $3.1 \pm 0.08,3.13 \pm 0.97$ and $3.16 \pm 1.1$ respectively. Also, there was a significant relationship between gender and hookah consumption with mental health $(P<0.01$ and $P<0.009)$.

Conclusion: Due to the low level of mental health in the dimensions of overcoming anger and anxiety and the student's role in securing and improving community health. The design of educational and promotional interventions to increase the anxiety management and anger management skills in the students is necessary to improve mental health of students.

Keywords: Self-assessment, Mental health, Students Paper Type: Research Article.

Citation (Vancouver): Solhi M, Pirouzeh R, Rahimi Khalifeh Kendi Z. Self-assessment of Mental Health Among Students of Iran University of Medical Sciences. Iran J Health Educ Health Promot. Autumn 2019;7(3):339 -348 . [Persian]

- Citation (APA): Solhi M., Pirouzeh R., Rahimi Khalifeh Kendi Z. (Autumn 2019). Self-assessment of Mental Health Among Students of Iran University of Medical Sciences. Iranian Journal of Health Education \& Health Promotion., 7(3),339-348. [Persian] 


\section{بروسى خودارزيابى سلامت روان در ميان دانشجويان دانشكاه علومبزنشكى ايران}

\section{4}

زمينه و هدف : دانشجويان دانشكاههاى علوميزشكى در دورههاى آموزشى خود در محيطهاى بالينى، با بال

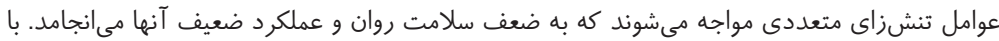

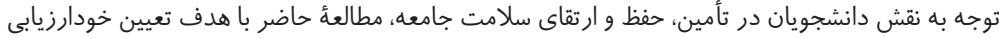

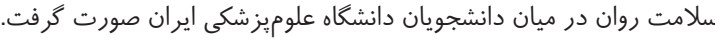

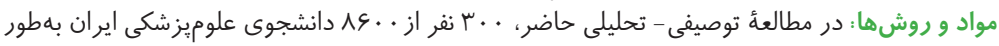

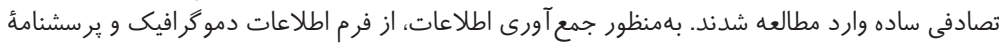

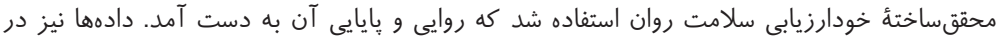

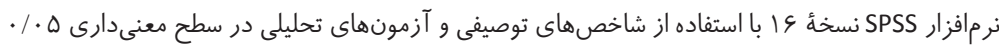
تجزيه و تحليل شد. تجران.

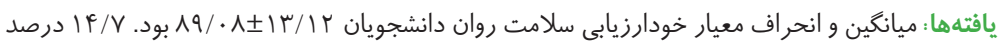

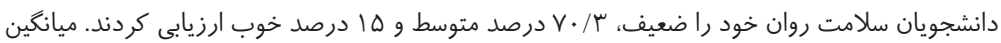
سن دانشجويان نيز

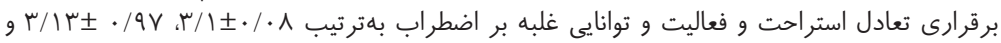

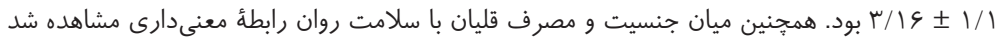

$$
\text { . }(\mathrm{P}<\cdot / .99, \mathrm{P}<\cdot / \cdot 1)
$$

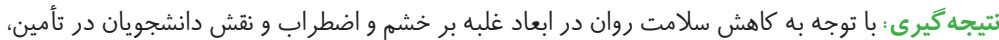

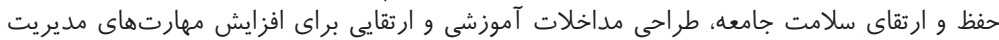

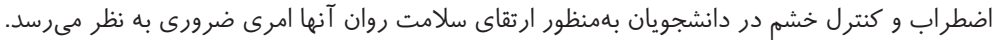

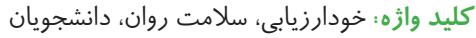

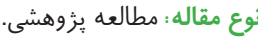

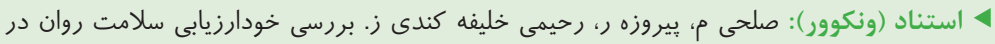

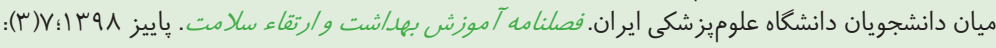
rFA-rmq

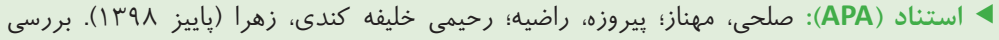

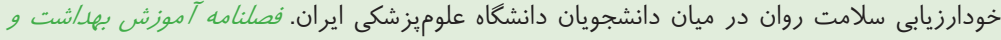

دانشيار، دكترى آموزش بهداشت، كروه آموزش

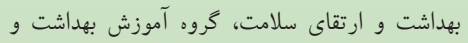

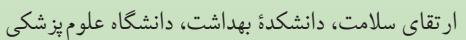

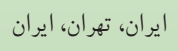

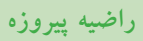

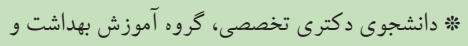

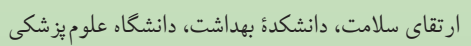
ايران، تهران، ايران (نويسندة مسئول): r_pirouzeh@yahoo.com

$$
\text { زهرا رحيمى خليفه كندى }
$$

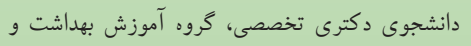

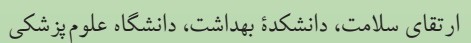

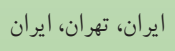

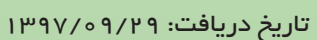

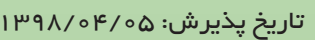



جايكاه عالى بيشرفت بازمى دارد. ورود به دانشكاه تغييرات عمدهاى

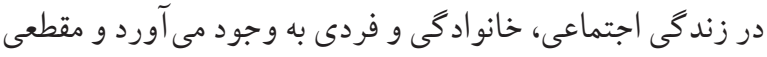

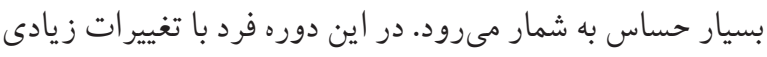

در سبك زندىى، تغذيه و روابط اجتماعى روبهرو مىشود (ه).

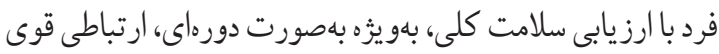
با ساير سنجشهاي موضـوعى و عينسى بهزيستى بيامدهاى سلامتى و

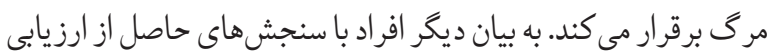

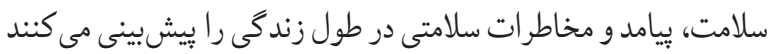

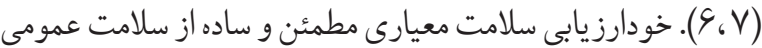
و شاخصى خوب از مر كومير و ناخوشى هاست كه بهشكلى وسيع در

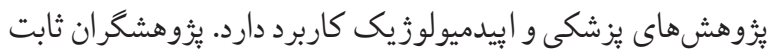

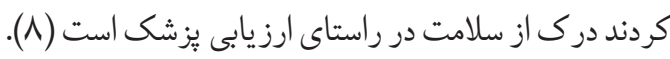
مطالعات متعددى بهنظور سنجش سلامت روان در دانشجويان انجام شده است (r، 9-4 (1). هريك از اين مطالعات به تعدادى از

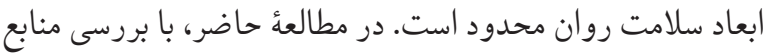
متعدد و ديدكاههاى متخصصان ابعاد مهم سلامت روان دانشجويان

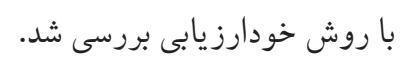

مو اد و روش ها

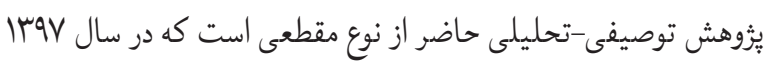
با هدف تعيين سلامت روان دانشجويان دانشحاه علوم يزشكى ايران صورت گرفت. جامعئ آمارى شامل دانشجويان دانشكاه علوم يزشكى

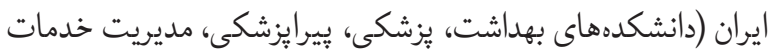

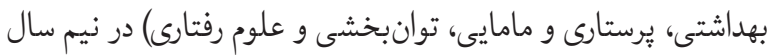

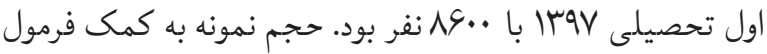

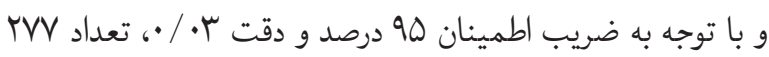

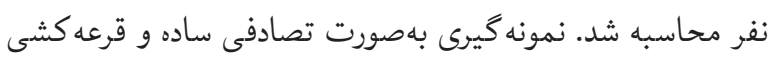

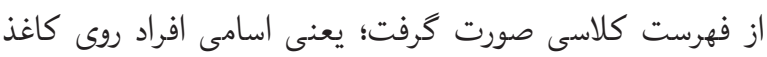
نوشته شد و در ظرفى قرار كرفت. سبيس از ميان اين اسامى افراد

سلامتى حق بشرى و هدفى اجتماعى در جهان به شمار مى آيد كه براى ارضاى نيازهاى اساسى و بهبود كيفيت زندكى انسان حياتى است. سازمان بهداشت جهانى، سلامت را وضعيت مطلوب فيزيكى، روانى و اجتماعى مى داندو تنها نبود بيماري را بهمنزلئ سلامتى تلقى نمى كند.

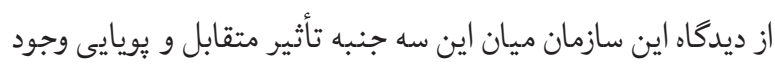

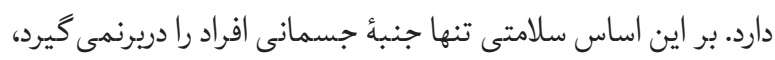

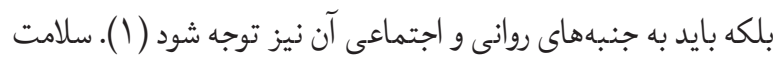
روان يكى از ابعاد مهم سلامتى و مرتبط با افكار، احساسات و رفتار است. به مجموعه عواملى كه در بيشخيرى از ايجاد يا بيشرفت روند وخامت اختلالات شناختى، احساسى و رفتارى در انسان نقشى مؤثر دارند، سلامت روان كفته مىشود. به عبارت ديكر، سلامت روان سطحى

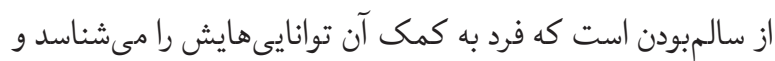
مى تواند بر استرسهاى طبيعى زندگى فائق آيد، كاركردى مؤثر داشته

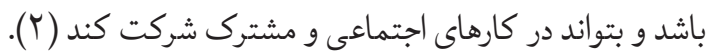
دورة تحصيلى دانشكاه بهدليل حضور عوامل متعدد ممكن است دورهاي همراه با فشار باشد. به عبارت ديكر، ورود به دانشكاه مقطعى داني بسيار حساس در زندگى نيروهاى كار آمد و فعال در هر كشورى

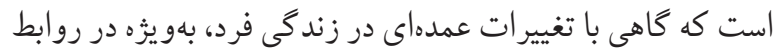

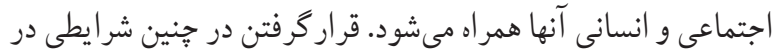

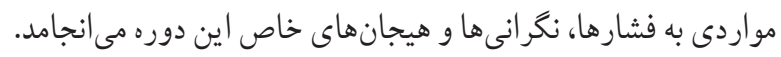

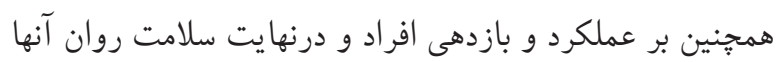

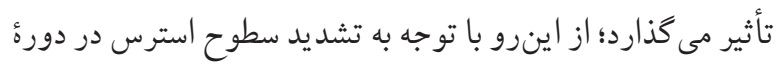

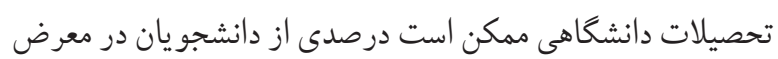
آسيب هاى ناشى از استرس باشند. دانشجويانى كه با سطوح بيشترى

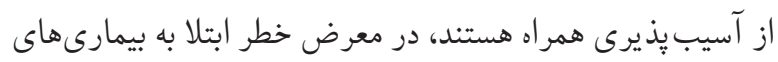

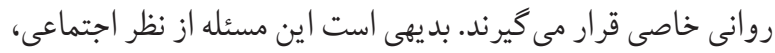
اقتصادى و سياسى در برنامهريزى كشور و ادارئ آن بسيار تأثير كذار است كه انتظار مىرود در آينده همين قشر به آن بيردازند (كا).

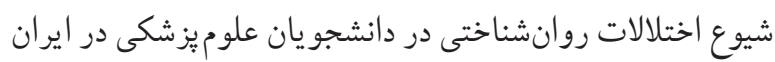
اب تا اله درصد كزارش شده است (†) . تشخيص اختلالات روانى دانى 
انتقاديذيرى، تو انايى مقابله با استرسهاى زندگى و مقابله با ناملايمات زندگى، مشار كت همه جانبه در زندگى، ارتباطات مثبت، توانايى تغيير،

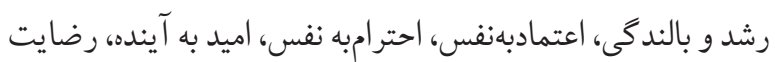
از زندگى، توانايى همدلى، توانايى برنامهريزى براى دستيابى به هدف، تهري،

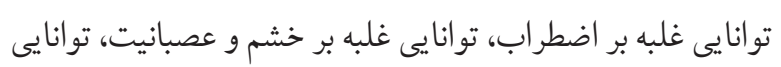
مسئوليت يذيرى، مهارت تصميم گيرى، ارتباط با خدا و ديندارى، بيان نيازها و خواستهها، مهارت نه كفتن و مهار كردن هيجان.

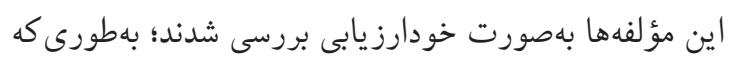

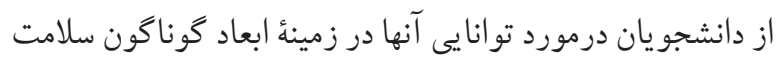

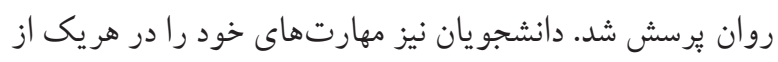

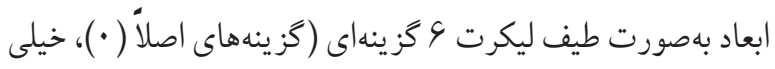

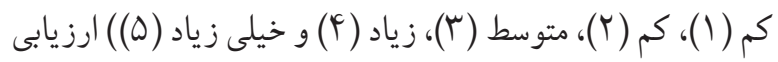
كردند. درنهايت سلامت روان دانشجو يان براساس ميانگين و انحراف

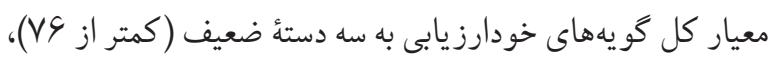

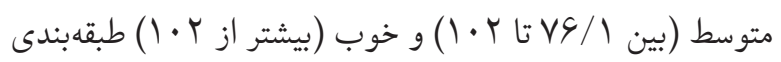

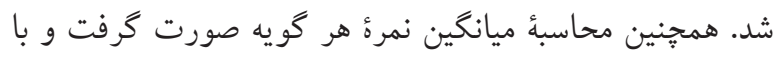

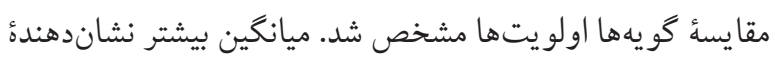

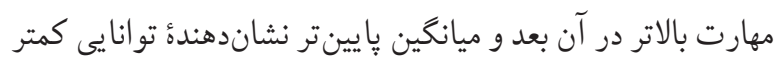
افراد در آن بعد از سلامت روان است.

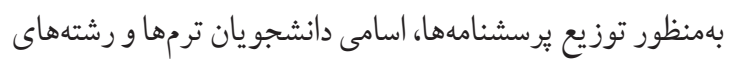

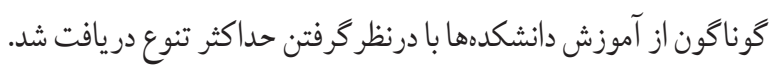

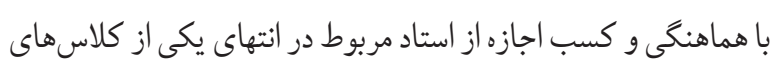
درسى، پس از معرفى و بيان اهداف مطالعه، در صورت تمايل و رضايت

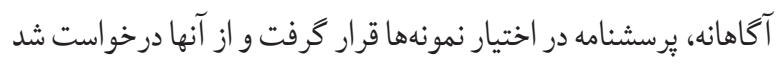
يرسشنامه را تكميل كنند. پِ از جمع آورى اطلاعات به كمى ابزار

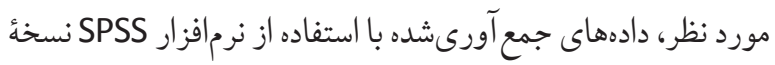

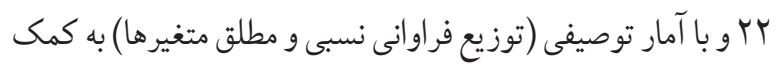
آزمونهاى تحليلى (ANOVA) تجزيه و تحليل شد. فاصلة اطمينان (P-value)

يافته ها

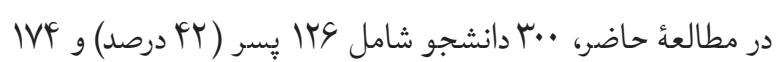

براى يثوهش انتخاب شدند. بهمنظور جلوكيرى از ريزش نمونها و و اطمينان بيشتر .با نمونه انتخاب شدند.

فرمول حجم نمونه توزيع نرمال P=• ت

معيارهاى ورود شامل رضايت آكاهانه از شركت در مطالعه، اشتغال به تحصيل در دانشكدههاى دانشعاه علوم يزشكى ايران، كذراندن حداقل يك ترم تحصيلى در دانشكده، نداشتن مشكلات جسمى حاد يا مزمن بنا به اظهار خود فرد، تمايل به شركت در مطالعه، نبودن دانشجويان در زمان امتحانات پايانت ترم است. معيارهاى خروج از مطالعه نيز علاقهنداشتن به شر كت در مطالعه و دانشجوى ترم اول بودن را شامل مى شود. ابزار جمع آورى اطلاعات شامل فرم مشخصات فردى و زمينهاى از قبيل سن، جنس، وضعيت تأهل، مقطع تحصيلى، سكونت، سيخار كشيدن، مصرف

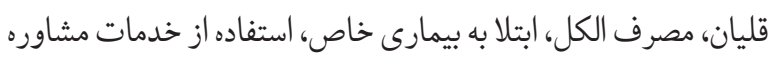

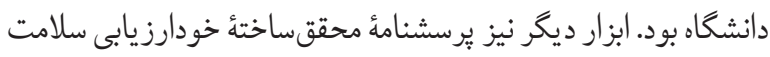

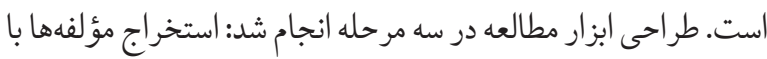
مرور منابع و مقالات مرتبط با سلامت روان، بررسى و تأييد مؤلفهها توسط متخصصان و سنجش اعتبار و پايايى ابزار. ينل متخصصان شامل متخصصان آموزش بهداشت و ارتقاى

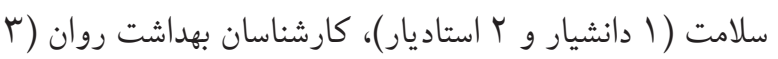
كارشناس روانشناسى) و ( يزشك عمومى است. مؤلفههاى حاصل

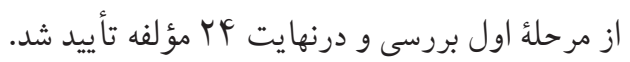

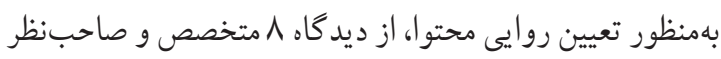
در رشتهُ آموزش بهداشت و ارتقاى سلامت و أ روانشناس استفاده

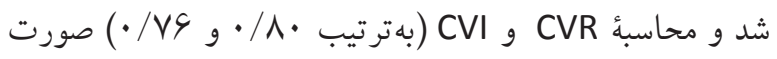

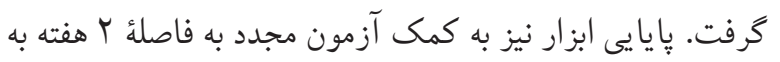

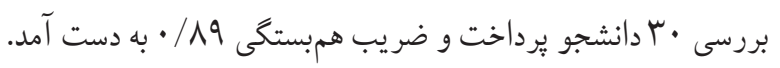

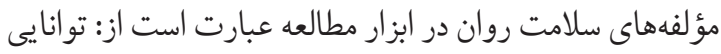
اجتماعى بودن و دورى از عزلت، شادابى و نشاط، توانايى برقرارى تعادل

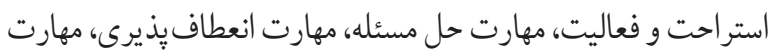


با توجه به ميانكين نمرءٔ ابعاد سلامت روان، توانايى غلبه بر

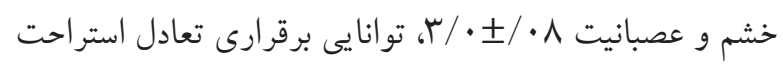

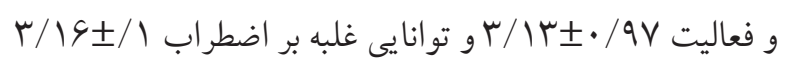

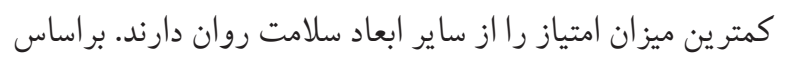

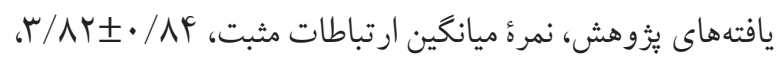

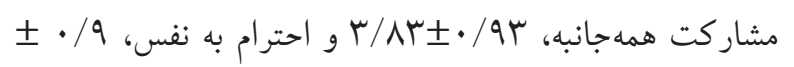

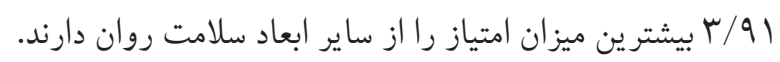

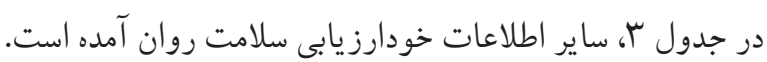
جدول س. فراوانى خودارزيابى ابعاد سلامت روانى دانشجويان

\begin{tabular}{|c|c|c|}
\hline ميانگين و انحراف معيار كويه & ابعاد سلامت روان & \\
\hline$r / V \varphi \pm \cdot / q$ & توانايى اجتماعىبودن و دورى از عزلت & 1 \\
\hline$r / s r \pm \cdot / 91$ & 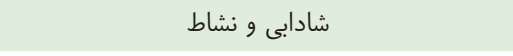 & r \\
\hline$r / 1 r \pm \cdot / 9 \gamma$ & توانايى برقرارى تعادل در استراحت و فعاليت & r \\
\hline$r / \Delta 9 \pm \cdot / \Lambda \varsigma$ & مهارت حل مسئله & r \\
\hline$r / s \uparrow \pm \cdot / \wedge \gamma$ & مهارت انعطاف يذيرى & $\Delta$ \\
\hline$r / f \mid \pm+1$ & مهارت انتقاديذيرى & 4 \\
\hline$r / \wedge \mu \pm \cdot / 9 \mu$ & توانايى مقابله با استرس هاى زندگى و ناملايمات زندگى & $\checkmark$ \\
\hline$r / \vee \wedge \pm \cdot / \wedge \vee$ & مشار كت همهجانبه در زندگى & $\wedge$ \\
\hline $\mathrm{r} / \Lambda \Lambda \pm \cdot / 94$ & 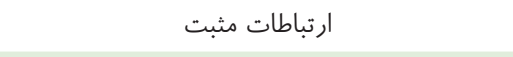 & 9 \\
\hline$\Upsilon / \vee \wedge \pm \cdot / \wedge \vee$ & توانايى تغيير در رشد و بالندگى & 1. \\
\hline$r / \wedge \Lambda \pm \cdot / 9 ૬$ & اعتمادبهنفس & 11 \\
\hline$r / 91 \pm \cdot / 9$ & 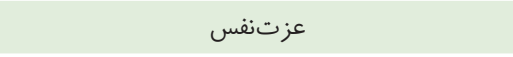 & ir \\
\hline 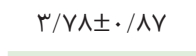 & اميد به آينده & $1 \pi$ \\
\hline$r / 11 \pm \cdot / 9 r$ & رضايت از زندگى & If \\
\hline$\Gamma / \Lambda \Lambda \pm \cdot / \wedge \Delta$ & 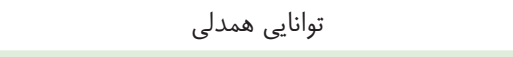 & 10 \\
\hline$r / r \varepsilon \pm 1 / . q$ & توانايى برنامهريزى براى دستيابى هدف & 19 \\
\hline$r / 19 \pm 1 / 1$ & ت انايى غلبه بر اضطراب & IV \\
\hline$r \pm 1 / \cdot 1$ & توانيى غلبه بر خشم و عصبانيت & 11 \\
\hline 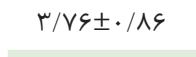 & توانايى مسئوليتيذيرى & 19 \\
\hline$r / s r \pm \cdot / q$ & مهارت تصميمگيرى & $r$. \\
\hline$r / 01 \pm \cdot / 99$ & ارتباط با خدا و ديندارى & rI \\
\hline$r / \mu s \pm \cdot / q \uparrow$ & بيان نيازها و خواستهها & rr \\
\hline$r / \mid v \pm 1 / \cdot 1$ & مهارت نه كفتن & r \\
\hline$\Gamma / \mu \perp \pm \cdot / 9 \vee$ & مهار كردن هيجان & rF \\
\hline
\end{tabular}

براساس آزمون Anova ميان جنسيت و ميانكين نمرءٔ سلامت

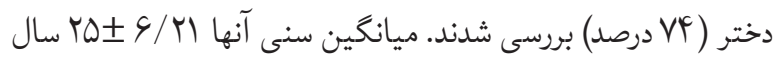

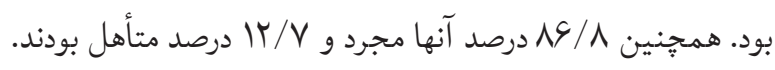
توزيع فراوانى دانشجويان براساس ساير متغير در جدول آمدرد آمدهاست. جدول ا. توزيع فراوانى متغير هاى جمعيتشناختى در جمعيت موردمطالعه

\begin{tabular}{|c|c|c|c|}
\hline درصد & فراوانى & \multicolumn{2}{|c|}{ متغير } \\
\hline$\Delta S$ & IVF & مؤنث & \multirow[b]{2}{*}{ جنس } \\
\hline qr & Irs & مذكر & \\
\hline$V \mu$ & $r 19$ & مجرد & \multirow{3}{*}{ 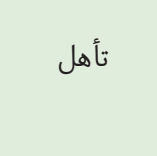 } \\
\hline$r \varphi / r$ & $\vee 9$ & متأهل & \\
\hline$\cdot / V$ & r & مطلقه & \\
\hline rN/V & $\wedge \varsigma$ & كارشناسى & \multirow{4}{*}{ مقطع تحصيلى } \\
\hline$\mu r / \mu$ & 1. & كارشناسى ارشد & \\
\hline IV & 01 & يزشكى & \\
\hline$r \cdot$ & s. & دكترى تخصصى & \\
\hline$p q / v$ & Ifq & خوابگاه & \multirow{3}{*}{ سكونت } \\
\hline r^/V & $\wedge \varsigma$ & استيجارى & \\
\hline$r I / r$ & 90 & شخصى & \\
\hline $\boldsymbol{c} / \mu$ & r & بله & \multirow{2}{*}{ سيغار كشيدن } \\
\hline $90 / V$ & YAV & خير & \\
\hline r & 9 & بله & \multirow[t]{2}{*}{ مصرف قليان } \\
\hline $9 \vee$ & rql & خير & \\
\hline $1 / \mu$ & r & بله & \multirow{2}{*}{ 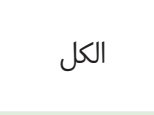 } \\
\hline $9 \wedge / \vee$ & rqs & خير & \\
\hline 1 & r & بله & \multirow{2}{*}{ داروى خاص } \\
\hline 99 & rqV & خير & \\
\hline
\end{tabular}

ميانكين و انحراف معيار خودارزيابى سلامت روان دانشجويان

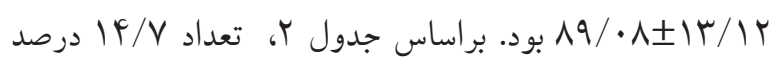

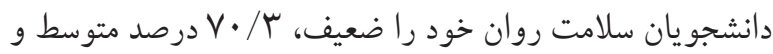
ه ا درصد خوب ارزيابى كردند. جدول r. فراوانى وضعيت خودارزيابى سلامت روان دانشجويان

\begin{tabular}{|c|c|c|}
\hline درصد & تعداد & طبقهبندى نمرة سلامت روان \\
\hline $1 \% / V$ & pq & ضعيف \\
\hline$V \cdot / \mu$ & $r \cdot 1$ & متوسط \\
\hline 10 & ro & 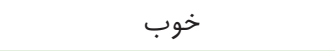 \\
\hline $1 \cdots$ & r... & جمع \\
\hline
\end{tabular}




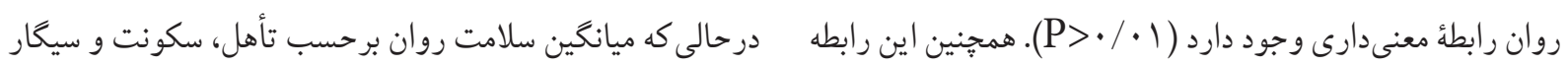

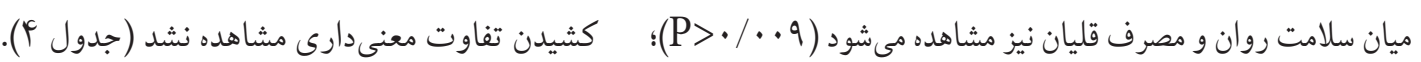

جدول عا. تعيين رابطة خودارزيابى ابعاد سلامت روان با متغيرهاى دموكَرافيك

\begin{tabular}{|c|c|c|c|c|c|}
\hline \multirow{2}{*}{ آزمون Anova } & \multicolumn{2}{|c|}{ فاصلة اطمينان } & \multirow{2}{*}{ ميانكين \ انحراف معيار } & \multirow{2}{*}{ دستهبندى } & \multirow{2}{*}{ متغير } \\
\hline & حد بالا & حد بايين & & & \\
\hline \multirow{2}{*}{${ }^{*} \mathrm{P}=\cdot / \cdot 11$} & $9 \cdot / 1$. & $\Lambda \Delta / \varsigma$. & $\Lambda V / \Lambda \Delta \pm I r / V V$ & مرد & \multirow{2}{*}{ 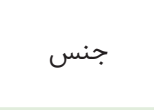 } \\
\hline & $\Lambda D / 9 F$ & $\Lambda r / r \Delta$ & $\Delta r / 1 \cdot \pm \mid r / r \mu$ & زن & \\
\hline \multirow{3}{*}{$\mathrm{P}=\cdot / 19$} & $\wedge V / F 1$ & $\wedge r / 9 \hookrightarrow$ & $\Lambda \Delta / 99 \pm 1 r / 9 \Delta$ & مجرد & \multirow{3}{*}{ ت ت أهل } \\
\hline & MN/Fr & $\wedge r / \cdot \vee$ & $\Lambda \Delta / V^{F} \pm 11 / 9 \mu$ & متأهل & \\
\hline & $\wedge \mathrm{V} / \wedge \Delta$ & $V \Delta / I f$ & $\Lambda \mathrm{I} / \Delta \cdot \pm \cdot / \mathrm{V}$ & مطلقه & \\
\hline \multirow{3}{*}{$\mathrm{P}=\cdot / 9 \wedge 9$} & $\wedge \vee / \wedge \mathrm{S}$ & $\wedge r / \Delta q$ & $\Lambda \Delta / V^{\mu} \pm 1 r / 19$ & خوابعاه & \multirow{3}{*}{ سكونت } \\
\hline & $\Lambda N / T^{\prime}$ & $\Lambda r / V r$ & $10 / 01 \pm 1 r / 99$ & استيجارى & \\
\hline & $\Lambda N / \uparrow q$ & $\wedge \mu / \cdot \vee$ & $\wedge \Delta / \vee \wedge \pm 1 \cdot / 91$ & شخصى & \\
\hline \multirow{2}{*}{$\mathrm{P}=\cdot / \Lambda \cdot \Lambda$} & $৭ ৯ / \vee \varsigma$ & $V r / 9 r$ & $\Lambda F / \Lambda F \pm \mid \Lambda / \cdot G$ & بله & \multirow{2}{*}{ مصرف سيعار } \\
\hline & $\wedge \vee / 10$ & $\Lambda r / r V$ & $\Lambda \Delta / \vee \perp \pm \cdot / r \vee$ & خير & \\
\hline \multirow{2}{*}{$* \mathrm{P}=\cdot / \cdot 9$} & $\Lambda s / r \vee$ & $S V / V Y$ & $\mathrm{~V} / \cdot \cdots \pm \cdot / \cdot \mathrm{V}$ & بله & \multirow{2}{*}{ مصرف قليان } \\
\hline & $\Lambda V / r q$ & $\Lambda s / \mathcal{R}$. & $\Lambda \Delta / \wedge \Delta \pm \mid r / F q$ & خير & \\
\hline
\end{tabular}

قا با توجه به جدول، ميان جنسيت و ابعاد سلامت روان، همجنين مصرف قليان و ابعاد سلامت روان ارتباطى معنى دار وجود دارد.

بحث

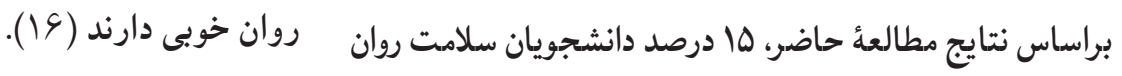

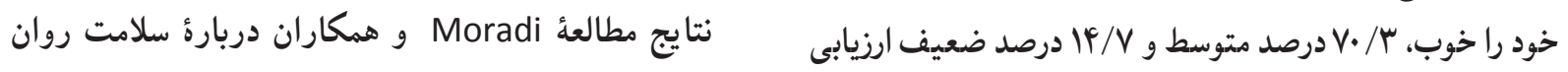

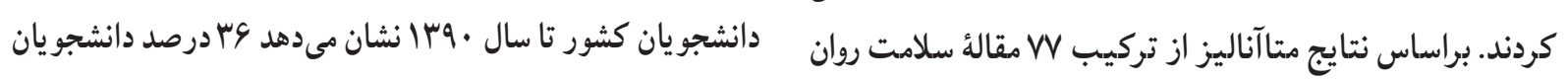

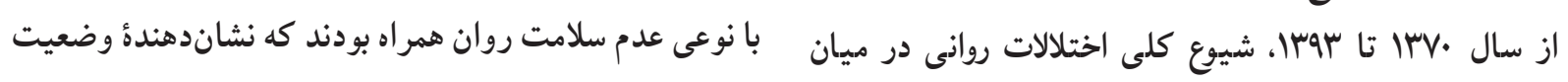

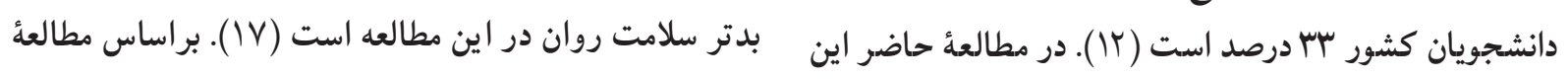

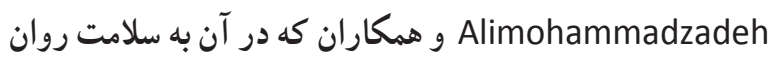

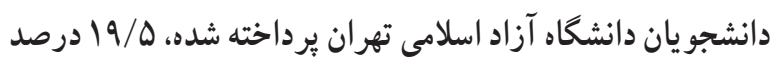

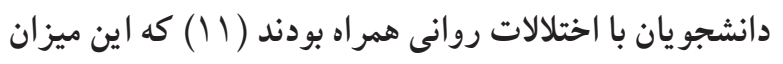

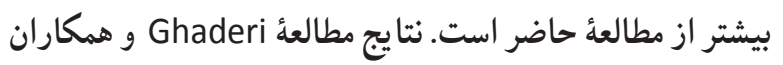

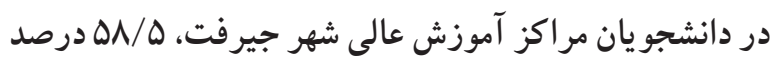

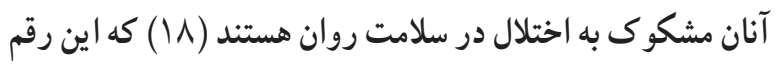
از مطالعهٔ حاضر بسيار بيشتر است. اين تفاوتها ممكن است به به رشتهُ تحصيلى دانشجو يان مربوط باشد. در مطالعهُ Ghaderi،

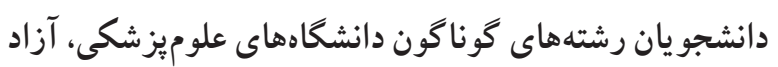

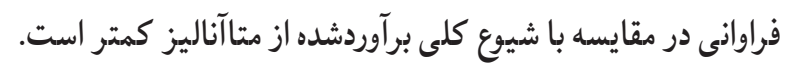
براساس مطالعهُ Hadavi و همكاران، وضعيت سلامت روان فران

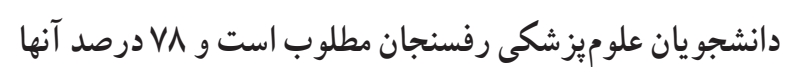

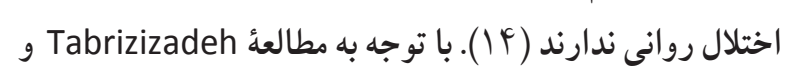

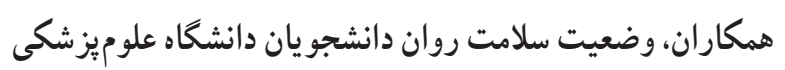
يزد إ99/ درصد است و دانشجو يان هيج اختلال روانى ندارند.

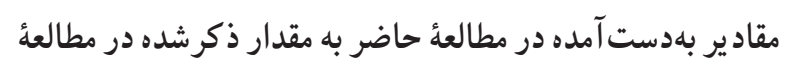

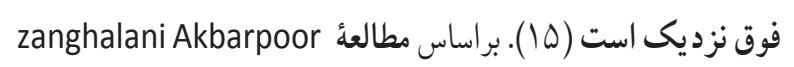

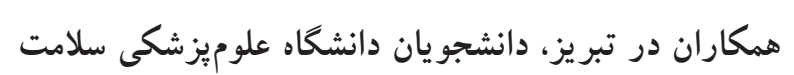


بsgari، بالا ارزيابى كردهاند. براساس مطالعهُ Zare و همكاران (YT)

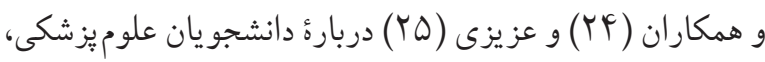
عزتنفس دانشجو يان در حد متوسط به بالاست كه اين امر با نتايج مطالعهُ حاضر مطابقت دارد. عزتنفس هستهٔ مركزى و ساختار

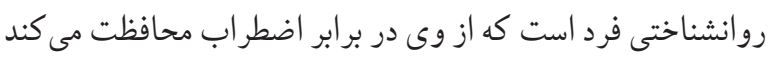

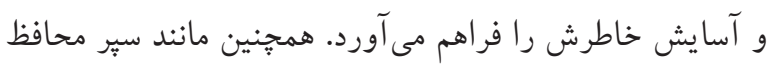

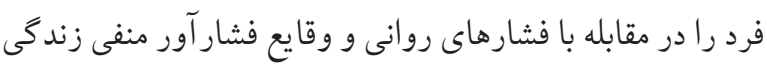

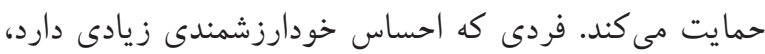

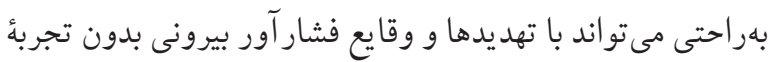

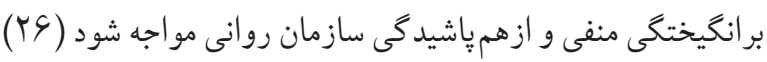

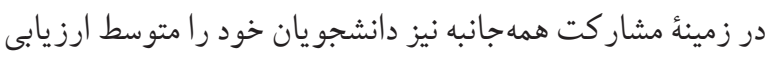

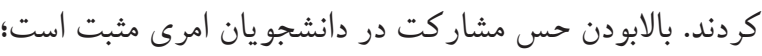

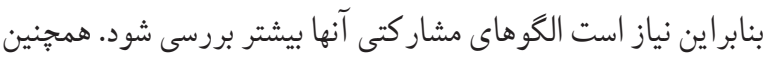
با مشاركت دانشجويان از طريق تشكلهاى دانشجويى منسجم مى توان اين احساس مشار كتى دانشجويان را ارتقا داد. براساس يافتهاى مطالعه حاضر، سلامت روان ارتباط معنىدارى إنى با جنسيت دارد؛ بهطورى كه ميانخين سلامت روان در مردان بيشتر باصن

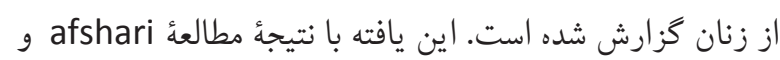

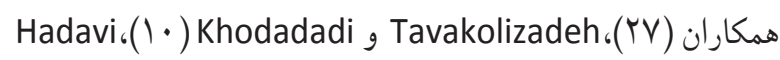

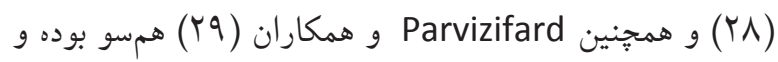
نشان مىدهد سلامت روان زنان پايين تر است. از سوى ديكر، نتايج

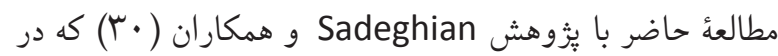

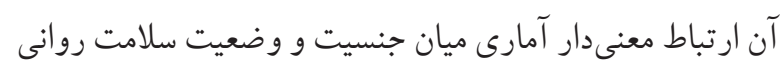

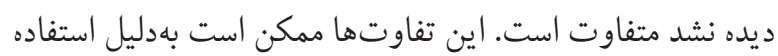

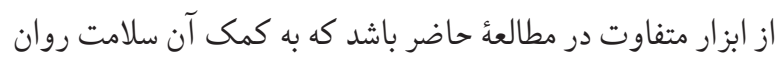
دانشجو يان بهصورت خودارزيابى و بهصورت كلى اندازه كيرى شد.

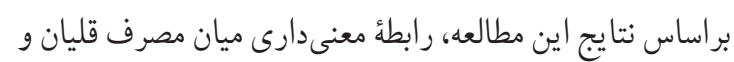

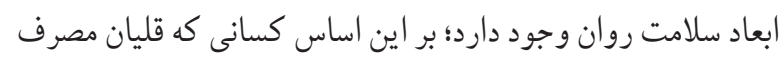
نمى كنند، سلامت روان بيشترى از افرادى كه قليان مصرف مى كنند،

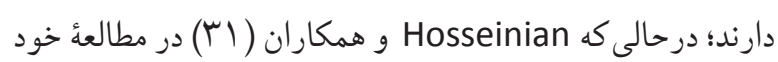
نتيجه گرفتند كه سلامت روان با مصرف قليان رابطهاى مستقيم
و ملى (1) و در مطالعة Alimohammadzadeh در دانشخاه آزاد بررسى شدند(11)؛ درحالى كه در مطالعهُ حاضر تنها به بررسى دانشجو يان يك دانشكاه برداخته شد.

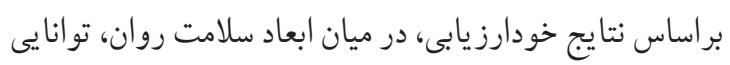
غلبه بر خشم و عصبانيت كمترين امتياز را دارد. در همين زمينه و وممكاران در بررسى ميزان كنترل خشم دانشجو يان دانشعاه

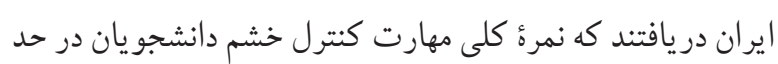
متوسط است كه اين بررسى نشاندهندة توانايى كمتر آنها در كنترل خشم است (19). هر خشمى بايد مديريت و كنترل شود، اما كاهى اهن

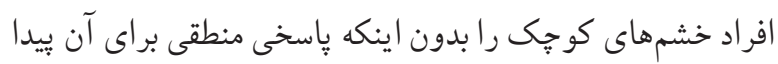

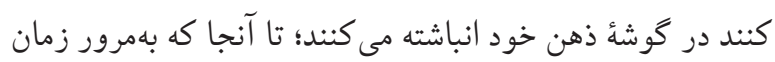

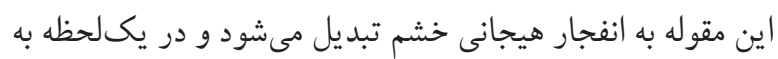

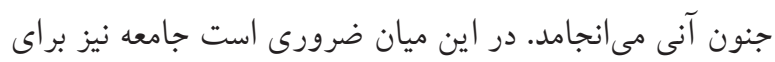

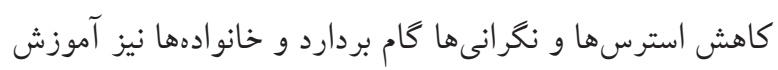
لازم بهمنظور كنترل خشم را فراموش نكنند تا شاهد تبعات منفى انفجار خشم و جنون آنى كه نتيجهُ بى توجهى به كنترل احساسات

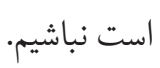
براساس يافتههاى مطالعهُ حاضر، ميانخين ميزان توانايى غلبه بر اضطراب كمتر از ساير ابعاد است. در مطالعهُ حاضر دانشجويان

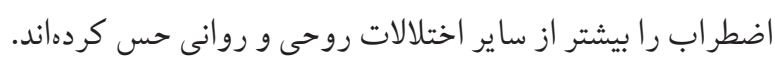

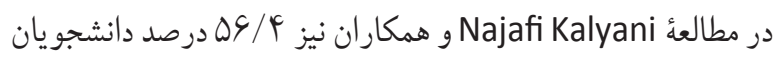

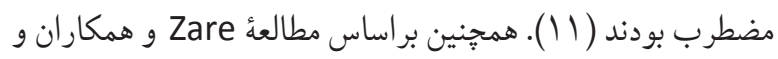
Rezaei اضطر اب هنخامى كه زندگى عادى را مشكل ساز كند داند ممكن داست

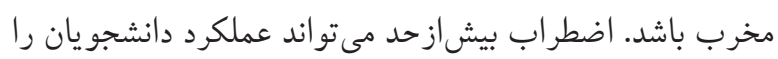

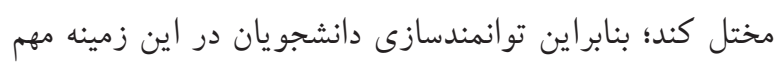

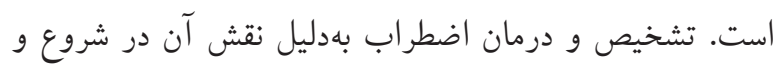

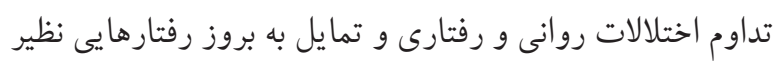

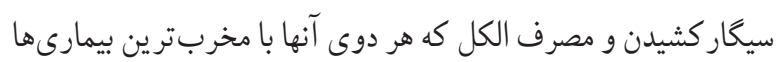
در ارتباط هستند اهميت فوق العادهاى دارد (Y (Y).

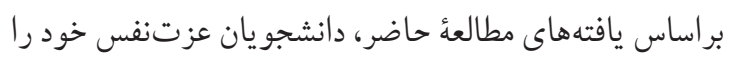


بايد توجه داشت كه سلامت روان از بعد غلبه بر خشم و اضطراب

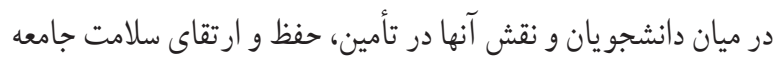

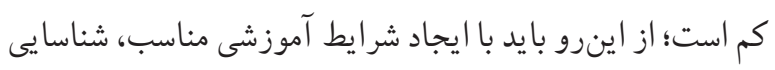

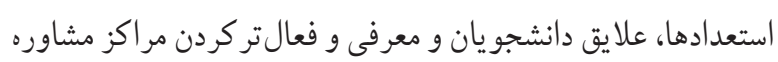

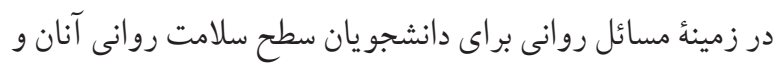

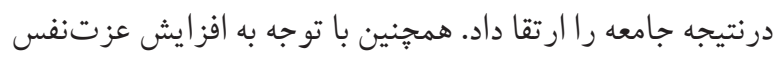

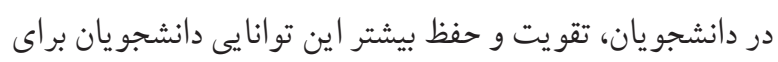
ييشرفتهاى تحصيلى و شغلى آنها امرى ضرورى است. نتيجان كيرى

دورة دانشجويى يكى از دورههاى جالش برانگيز زندكى هر فرد است؛

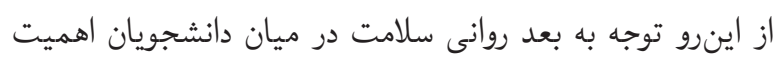

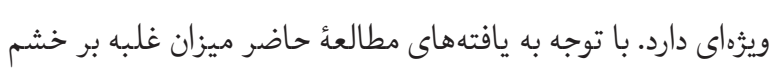

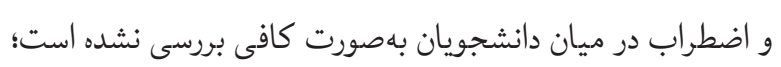

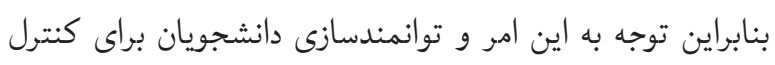
بر خشم و اضطراب آنها امرى ضرورى بهمنظور ارتقاى سلامت توند دانشجويان و جامعه است.

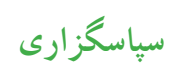

از دانشجويان، اعضاى هيئتعلمى و كارشناسان مركز مشاورة

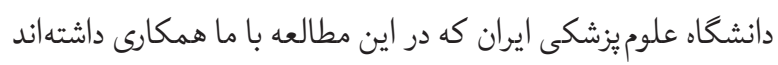

$$
\text { كمال تشكر و قدردانى را داريم. }
$$

سهم تمامى نويسندكان در اين مطالعه يكسان است و هيجٍُونه تضاد منافعى وجود ندارد.

\section{References}

1. Namazi A, AlizadehS, Kouchakzadeh-TalamiS. The correlation between general health, emotional intelligence and academic achievement together on midwifery students. Journal of Clinical Nursing and Midwifery. 2015;4(2):20-8.

2. Shadi M, Peyman N, Taghipour A, Tehrani H. Predictors of the academic stress and its determinants among students based on the theory of planned behavior. Journal of Fundamentals of Mental Health. 2017;20(1):87-98.7. [DOI:10.22038/jfmh.2017.10060]

3. Mosavy M. The comparative study of health status of medical
و معنى دارى دارد. همجنين انخيزهُ مصرف قليان براى افرادى كه

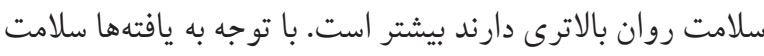
روان هم عامل بازدارنده و هم عامل محرك براى مصرف قليان

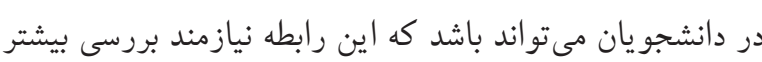

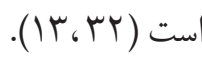
يافتهاى مطالعهُ حاضر نشان مىدهد ميان ابعاد سلامت روان،

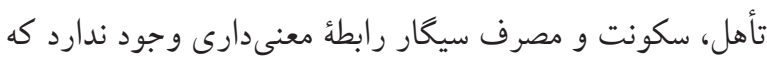

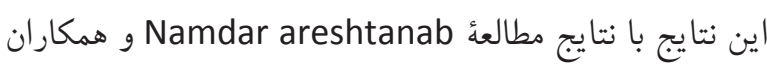
مطابقت دارد. همجنين Jahani Hashemi در مطالعهُ خود نتيجه كرفت كه ميان سكونت و سلامت روان رابطةٌ معنىدارى وجود ندارد

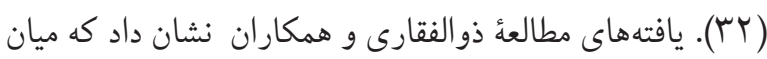

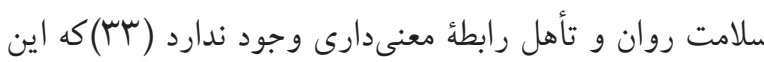

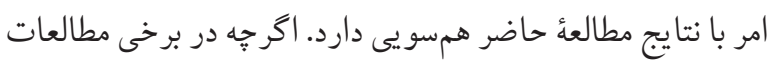

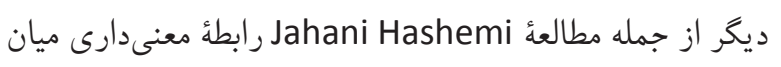
تأهل و سلامت روان وجود دارد (Tr).

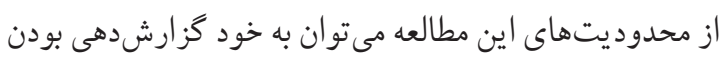
روش سنجش سلامت روان از سوى دانشجويان اشاره كرد كه البته

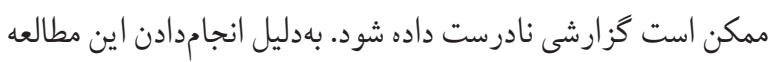

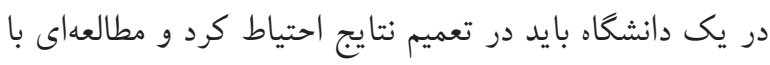

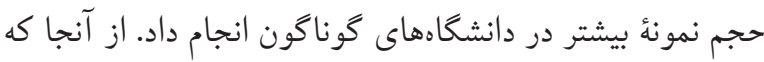

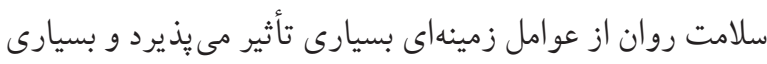

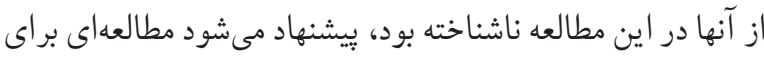

$$
\text { شناسايى بيشتر اين عوامل صورت بخيرد. }
$$

students and para-medical students trainee. Journal of Gorgan University of Medical Sciences. 2004;6(1):101-7.

4. Sohrabi M-R, Malih N, Karimi H-R, Hajihashemi Z. Effect of General MedicalDegreeCurricularChangeonMentalHealth of Medical Students: A Concurrent Controlled Educational Trial. Iranian Journal of Psychiatry. 2019;14(1):40-6. https://doi.org/10.18502/ijps.v14i1.421 PMid:31114616 PMCid:PMC6505047

5. Shahabinejad M, Sadeghi T, Salem Z. Assessment the mental health of Nursing. Journal 
of Nursing Education. 2016;4(2):29-37. https://doi.org/10.21859/ijpn-04024

6. McCullough ME, Laurenceau JP. Gender and the natural history of self-rated health: a 59-year longitudinal study. Health psychology: officialjournal of the Division of Health Psychology, American Psychological Association. 2004;23(6):651-5. https://doi.org/10.1037/0278-6133.23.6.651 PMid:15546234

7. Manderbacka K, Kåreholt I, Martikainen $\mathrm{P}$, Lundberg O. The effect of point of reference on the association between self-rated health and mortality. Social science \& medicine. 2003;56(7):1447-52. https://doi.org/10.1016/S0277-9536(02)00141-7

8. Bakouei S, Bakouei F, Raisi M, Ahmari Tehrani H, Dehghan H. Self-reported Health and Health-promoting Behaviors in Women of Reproductive Age. Journal of Babol University of Medical Sciences. 2017;19(3):29-37. https://doi.org/10.1177/0272684X17747053 PMid:29228883

9. Tavabi AA, Iran-Pour E. The association between religious beliefs and mental health amongst medical students. JPMA The Journal of the Pakistan Medical Association. 2011;61(2):135-8.

10. Tavakolizadeh J, Khodadadi Z. Assessment of mental health among freshmen entering the first semester in Gonabad University of Medical Sciences in 2009-2010. The horizon of medical sciences. 2010;16(2):45-51.

11. Alimohammadzadeh $K$, Akhlaghdoust $M$, Bahrainian SA, Mirzaei A. Survey on Mental Health of Iranian Medical Students: A Cross-sectional Study in Islamic Azad University. Shiraz E-Medical Journal. 2017;18(7). https://doi.org/10.5812/semj.14929

12. Zare N, Parvareh M, Nouri B, Namdari M. Mental health status of Iranian university students using the GHQ-28: a meta-analysis. Sci J Kurdistan Univ Med Sci. 2016 Jan 1;21:1-6.

13. Namdar areshtanab $\mathrm{H}$, ebrahimi $\mathrm{H}$, sahebihagh $\mathrm{M}$, arshadi bostanabad M. Mental Health and Its Relationship with Academic Achievement in Students of Tabriz NursingMidwifery Faculty. Iranian Journal of Medical Education. 2013;13(2):146-52.

14. Hadavi M, Yazdani M, Khodadadi A, Hashemi Z, Aminzadeh F. Comparison of the Mental Health Status of First-and last-year students of Nursing, Midwifery and Paramedical Faculty of Rafsanjan based on SCL90 in 2012. Journal of Rafsanjan University of Medical Sciences. 2014;13(6):54960.

15. TABRIZIZADEH M, YASINI AS, Rostamzade $P$, Zare $M$. The mental health status of students of Medicine and Dentistry; a study in Shahid Sadoughi University of Medical
Sciences, Yazd, Iran.

16. Akbarpoor zanghalani MB, khodayari shouti S, Malekzadeh A. The Relationship between Mental Health and Achievement Motivation among the Students of Tabriz University of Medical Sciences. Development Strategies in Medical Education. 2016;3(2):14-24.

17. Moradi A, Alilou M, Peyroovi M. Reviews General Health the Country University Students. Procceding of the First Seminar on Mental Health. 2002; Tehran, Ministry of Science. Research and Technology. [In Persian].

18. Ghaderi M, Hardani F, Nasiri M, Fakouri E. Assessment of mental health and its related factors in Jiroft students of higher education centers in 2013. Journal of Rafsanjan University of Medical Sciences. 2015;13(10):949-60.

19.SolhiM,MohammadaliL.StatusofAngerControlSkillsinStudents. Military Caring Sciences Journal. 2016 Mar 15;2(4):238-45. https://doi.org/10.18869/acadpub.mcs.2.4.238

20. Najafi Kalyani M, Pourjam E, Jamshidi N, Karimi S, Najafi Kalyani V. Survey of stress, anxiety, depression and selfconcept of students of Fasa University of medical sciences, 2010. Journal of Fasa University of Medical Sciences. 2013 Sep 15;3(3):235-40.

21. Rezaei-Adryani M, Azadi A, Ahmadi F, Azimi A. Comparison level of stress, Anxiety, Depression and quality of life in dormitory resident students. Iranian Journal of Nursing Research. 2007;4(2):31-8.

22. Ghasemnegad SM, Barchordary M. Frequency of anxiety and its relation with depression and other individual characteristics in nursing students. Journal of Holistic Nursing and Midwifery. 2012;22(2):0-.

23. Zare N, Daneshpajooh F, Amini M, Razeghi M, Fallahzadeh $\mathrm{MH}$. The relationship between self-esteem, general health and academic achievement in students of Shiraz University of Medical Sciences. Iranian journal of medical education. 2007 Jun 15;7(1):59-67.

24. Asgari F, Mirzaee M, Tabari R, Kazemnejad Leili E. Selfesteem in students of Guilan University of Medical Sciences. Research in Medical Education. 2016 Jul 15;8(2):18-26. https://doi.org/10.18869/acadpub.rme.8.2.18

25. Azizi M, Khamseh F, Rahimi A, Barati M. The relationship between self-esteem and depression in nursing students of a selected medical university in Tehran. IJPN. 2013; 1 (1) :28-34 .

26. Hosseini MA, Dejkam M, Mirlashari J. Correlation between Academic Achievement and Self-esteem in Rehabilitation Students in Tehran University of Social Welfare \& Rehabilitation. Iranian journal of medical education. 2007 Jun 15;7(1):137-42.

27. afshari $Z$, rakhshani $M$. Factors related to mental health 
of students in Zabol University of Medical Sciences. J Neyshabur Univ Med Sci. 2014 Aug 1;2(3):28-36.

28. Hadavi M, Yazdani M, Khodadadi A, Hashemi Z, Aminzadeh F. Comparison of the Mental Health Status of First-and last-year students of Nursing, Midwifery and Paramedical Faculty of Rafsanjan based on SCL90 in 2012. Journal of Rafsanjan University of Medical Sciences. 2014;13(6):54960.

29. Parvizifard AA, Shakeri J, Sadeqhi K, Ameri MR, Nezhadjafar P. Psychiatric disorders in first year students of Kermanshah University of medical sciences (2002). Journal of Kermanshah University of Medical Sciences (J Kermanshah Univ Med Sci). 2006 Jul 6;10(2).

30. Sadeghian E, Farhadi Nasab A, Falahinia GH. The study of mental health status in students of Hamadan University of Medical Sciences in 2006. Journal of Evolution and Development of Medical Education. 2009;1(1):44-53.
31. Hosseinian M, Noury R, Moghadasin M, Esalatmanesh S Study of the mediating role of mental health and motives for substance use in the relationship between adjustment to university and cigarette and water-pipe use among the students. Feyz Journal of Kashan University of Medical Sciences. 2018;22(2):192-205.

32. Jahani Hashemi $H$, Rahimzadeh Mirmahalleh $S$, Ghafelehbashy H, Sarichloo ME. Investigating the mental health of the first-and last-year students of QUMS (2005). The Journal of Qazvin University of Medical Sciences. 2008 Aug 10;12(2):42-9.

33. Zolfaghari, A. R., D. Fathi and M. Hashemi (2011). "The Study of Mental Health Status of Payame-Noor University Students in Toyserkan, Iran." Procedia - Social and Behavioral Sciences 30: 1795-1797. . https://doi.org/10.1016/j.sbspro.2011.10.345 